\title{
Passivating electron contact based on highly crystalline nanostructured silicon oxide layers for silicon solar cells
}

\author{
Josua Stuckelberger ${ }^{1}$, Gizem Nogay ${ }^{1}$, Philippe Wyss ${ }^{1}$, Quentin Jeangros ${ }^{1}$, Christophe Allebé ${ }^{2}$, Fabien Debrot ${ }^{2}$, Xavier Niquille ${ }^{1}$, Martin \\ Ledinsky ${ }^{3}$, Antonin Fejfar ${ }^{3}$, Matthieu Despeisse ${ }^{2}$, Franz-Josef Haug ${ }^{1}$, Philipp Löper ${ }^{1}$, Christophe Ballif ${ }^{1}$ \\ ${ }^{1}$ École Polytechnique Fédérale de Lausanne (EPFL), Institute of Microengineering (IMT), Photovoltaics and Thin-Film Electronics \\ Laboratory, Rue de la Maladière 71b, 2002 Neuchâtel, Switzerland \\ ${ }^{2}$ CSEM PV-Center, Jaquet-Droz 1. 2002 Neuchâtel, Switzerland \\ ${ }^{3}$ Laboratory of Nanostructures and Nanomaterials, Institute of Physics, Academy of Sciences of the Czech Republic, v. v. i., \\ Cukrovarnická 10, 16200 Prague, Czech Republic
}

\begin{abstract}
We present a novel passivating contact structure based on a nanostructured siliconbased layer. Traditional poly-Si junctions feature excellent junction characteristics but their optical absorption induces current losses when applied to the solar cell front side. Targeting enhanced transparency, the poly-Si layer is replaced with a double-layer stack consisting of a nanostructured silicon oxide capped with a nanocrystalline silicon (nc-Si) layer. The nanostructured silicon oxide layer consists of an amorphous $\mathrm{SiO}_{\mathrm{x}}$ matrix with incorporated Si filaments connecting one side of the layer to the other, and is referred to as nanocrystalline silicon oxide $\left(\mathrm{nc}-\mathrm{SiO}_{\mathrm{x}}\right.$ ) layer. We investigate passivation quality, measured as saturation current density, and nanostructural changes, characterized by Raman spectroscopy and transmission electron microscopy, carefully studying the influence of annealing dwell temperature. Excellent surface passivation on n-type and also p-type wafers is shown. An optimum annealing temperature of $950{ }^{\circ} \mathrm{C}$ is found, resulting in a saturation current density of $8.8 \mathrm{fA} \mathrm{cm}^{-2}$ and $11.0 \mathrm{fA} \mathrm{cm}^{-2}$ for n-type and p-type wafers, respectively. Efficient current extraction is presented with specific contact resistivities of $86 \mathrm{~m} \Omega \mathrm{cm}^{2}$ on n-type wafer and $19 \mathrm{~m} \Omega \mathrm{cm}^{2}$ on p-type wafers, respectively. Highresolution transmission electron microscopy reveals that the layer stack consists of intermixed $\mathrm{SiO}_{x}$ and $\mathrm{Si}$ phases with the $\mathrm{Si}$ phases being partly crystalline already in the asdeposited state. Thermal annealing at temperatures $\geq 850{ }^{\circ} \mathrm{C}$ further promotes crystallization of the Si-rich regions. We show that the addition of the $\mathrm{SiO}_{\mathrm{x}}$ phase enhances the thermal stability of the contact and we expect it to allow to tune the refractive index and improve transparency while still providing efficient electrical transport thanks to the crystalline Si phase, which extends throughout almost the entire layer.
\end{abstract}

\section{INTRODUCTION}

Crystalline silicon (c-Si) solar cells have a market share of $>90 \%$ [1] and represent the most mature and promising photovoltaic technology to replace fossil fuels and nuclear energy sources. In most $\mathrm{c}-\mathrm{Si}$ solar cells the $\mathrm{Si}$ wafer is in direct contact with the metallization, forming a metallurgical c-Si/metal junction. The direct metal-silicon interface is affected by very high recombination rates, resulting in a decrease of the solar cell's photovoltage and therefore energy conversion efficiency [2]. This voltage loss can be overcome by inserting passivating buffer layers between the silicon wafer and the metal contact. First approaches, based on thin silicon oxide buffer layers capped with doped poly-silicon or semi-insulating poly-silicon (SIPOS) were pioneered already in the 1980's [3]-[5]. Recently, impressive solar cell results were demonstrated using a similar approach as rear contact [6]-[9], with associated recombination current at the rear side of only $7 \mathrm{fA}$ $\mathrm{cm}^{-2}$ [10]. This contact structure is based on a very thin $\mathrm{SiO}_{2}$ buffer layer coated by a highly doped silicon layer. During a thermal annealing step at typically $800-900{ }^{\circ} \mathrm{C}$, dopants diffuse from the deposited silicon layer into the wafer forming a highly doped 
region. Afterwards, a hydrogenation step [11] is applied to chemically passivate electronic defects at the wafer-SiO 2 interface to "switch on" the passivation [6].

With the excellent quality of poly-Si junctions employed as rear contact, the front side contacting scheme becomes the efficiency limiting element [10]. Consequently, in order to further increase the solar cell efficiency, passivating contacts are also needed at the front side.

While requirements for a full-area passivating front contact are similar to these for the rear contact in terms of passivation behavior and electrical transport, the front contact layer stack also has to be optically highly transparent to avoid parasitic absorption losses.

This can be achieved with thin and highly crystalline silicon layers since the absorption coefficient of crystalline silicon in the visible and infrared is much lower than of amorphous silicon. Full crystallization of thin Si layers can be reached by prolonged thermal annealing [12]. This might, however, lead to deteriorated surface passivation due to rupture of the $\mathrm{SiO}_{\mathrm{x}}$ buffer layer [6], [13]-[15]. Alternatively, thicker $\mathrm{SiO}_{2}$ buffer layers can be used [5], [7], but this approach requires a " $\mathrm{SiO}_{2}$ break up" step at $1050{ }^{\circ} \mathrm{C}$ which might degrade surface passivation or alter the doping profile in an unwanted way. To overcome these limitations, we propose to choose deposition regimes that result in crystalline structures in the film already before thermal annealing, such that moderate temperatures $\left(700-900{ }^{\circ} \mathrm{C}\right)$ are sufficient to achieve almost full crystallization.

To further decrease optical absorption we introduce a high band gap material, namely silicon oxide, as a matrix around the silicon crystallites. The added $\mathrm{SiO}_{\mathrm{x}}$ phase gives the opportunity to tune the refractive index of the mixed-phase material [16]. The concept of $\mathrm{Si}$ phases embedded in a $\mathrm{SiO}_{\mathrm{x}}$ matrix is related to the early work on SIPOS-based junctions [3], [4], [17], [18]. SIPOS is a homogeneous material with Si inclusions surrounded by $\mathrm{SiO}_{2}$ phases and features rather high specific resistances due to the transport barrier caused by the $\mathrm{Si} / \mathrm{SiO}_{2}$ band offsets.

In contrast to SIPOS like approach, we propose in this paper a layer structure in which the Si phases extend as pillars or filaments from one side to the other of the layer, thus enabling efficient current transport across the layer. We present an electron-selective passivating junction layer stack consisting of a phosphorus-doped $\mathrm{nc}-\mathrm{SiO} \times \mathrm{xc}-\mathrm{Si}$ double layer on top of a chemical oxide, prepared by plasma enhanced chemical vapor deposition (PECVD) and a thermal annealing step. The contact is investigated as $n+/ n$ and as $n+/ p$ junction using both $n$ - and p-type wafers, respectively. We discuss the effect of annealing dwell temperature on passivation properties and nanostructural transformations.

\section{EXPERIMENTAL}

The investigation of the passivating electron contact was done using symmetrical structures based on $280 \mu \mathrm{m}$ thick double side polished 4-inch (100) $2.8 \Omega \mathrm{cm}$ silicon wafers doped with phosphorus or boron (Figure 1). After cleaning using standard wet chemistry, a $1.2 \mathrm{~nm}$ thin $\mathrm{SiO}_{\mathrm{x}}$ layer was formed by wet chemical oxidation [19], [20], also referred to as "chemical $\mathrm{SiO}_{\mathrm{x}}$ ". Subsequently, a phosphorus-doped $\mathrm{SiO}_{\mathrm{x}} / \mathrm{Si}$ bilayer structure was deposited by PECVD on both sides. The individual layers are also referred to as "deposited $\mathrm{SiO}_{\mathrm{x}}$ " and "deposited $\mathrm{Si}$ " in order to distinguish from the chemical $\mathrm{SiO}_{\mathrm{x}}$. The samples were then annealed for 15 minutes in nitrogen $\left(\mathrm{N}_{2}\right)$ atmosphere at temperatures from $750{ }^{\circ} \mathrm{C}$ to $950{ }^{\circ} \mathrm{C}$. This was followed by a 30 min forming gas $\left(4 \% \mathrm{H}_{2}\right.$ in $\left.\mathrm{N}_{2}\right)$ anneal at $500{ }^{\circ} \mathrm{C}$ to passivate electronic defects at the wafer-SiO ${ }_{x}$ interface. The effective minority carrier lifetime was measured by photoconductance decay and the method of Kane and Swanson [21] was applied to extract the emitter saturation current density at an excess carrier density of $1 \cdot 10^{16} \mathrm{~cm}^{-3}$. The spatial homogeneity of the passivation was analyzed using photoluminescence imaging (PLI). The doping profile was analyzed by secondary 
ion mass spectroscopy (SIMS) with a Cameca ims 4f-E6. For electrical characterization, coplanar aluminium (Al) contacts were thermally evaporated, and the specific contact resistivity was measured using the transfer length method (TLM). Crystallization of the Si phases and stress in the layer was characterized by Raman spectroscopy. Care was taken to suppress the signal of the silicon wafer in order to get a clear signal only from the deposited layers. This was done using a $442 \mathrm{~nm}$ laser, which has a Raman collection depth of only around $150 \mathrm{~nm}$ in c-Si [22], and additionally by polarizing the laser in such a way that the signal from the underlying wafer was minimized [23].

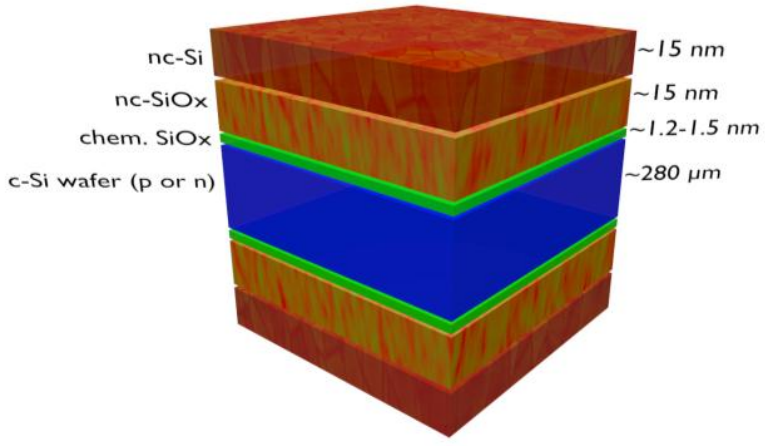

FIG. 1. Schematic of the symmetrical samples with the $n c-S i O_{x} / n c-S i$ carrier-selective junction stack. The mixed-phase layer is indicated by silicon phases (red) embedded in an oxide matrix (green).

The structural changes were further characterized by several transmission electron microscopy (TEM) techniques in a FEI Titan Themis. The microscope was operated at $300 \mathrm{kV}$ for experiments involving high-resolution (HR) TEM and scanning TEM (STEM) high-angle annular dark field (HAADF) imaging combined with energy-dispersive X-ray spectroscopy (EDX) and at $200 \mathrm{kV}$ for STEM electron energy-loss spectroscopy (EELS) measurements, which were performed with a convergence of $28 \mathrm{mrad}$ and a similar collection angle using a Gatan GIF Quantum ERS high energy resolution EELS spectrometer and energy filter (dispersion of $0.1 \mathrm{eV}$ per channel). To this purpose, TEM lamellae were prepared from samples that were either as-deposited or annealed at $850{ }^{\circ} \mathrm{C}$ or $900{ }^{\circ} \mathrm{C}$ using the conventional focused ion beam (FIB) lift-out technique in a Zeiss Nvision 40.

\section{RESULTS AND DISCUSSION}

\subsection{Surface passivation}

We investigated the effect of the additional silicon oxide phase in our deposited passivating layer stack by varying the deposition time of the $\mathrm{nc}-\mathrm{SiO}_{\mathrm{x}}$ layer while keeping the total deposition time of the $\mathrm{nc}_{-} \mathrm{SiO}_{\mathrm{x}} / \mathrm{nc}-\mathrm{Si}$ stack constant. The implied open-circuit voltage $\mathrm{i} V_{\mathrm{OC}}$ and the emitter saturation current $J_{0}$ after annealing at $900{ }^{\circ} \mathrm{C}$ are plotted in Figure $2 \mathrm{a}$ for $\mathrm{n}$-type wafers. The surface passivation is clearly enhanced with increasing nc-SiO $\mathrm{x}_{\mathrm{x}}$ thickness.

Additionally, we tested the tolerance of our contact structure to variations of dwell temperature for the case of a stack with $36 \% \mathrm{nc}^{-\mathrm{SiO}_{\mathrm{x}}}$ relative deposition time. The dependence of $\mathrm{i} V_{\mathrm{OC}}$ and $J_{0}$ on annealing dwell temperature is shown in Figure 2 for $\mathrm{n}+\mathrm{p}$ junctions (b) and $\mathrm{n}+/ \mathrm{n}$ junctions (c). Excellent surface passivation is achieved for temperatures above $850{ }^{\circ} \mathrm{C}$ up to $950{ }^{\circ} \mathrm{C}$ for both n- and p-type wafers. In other studies, where the doped $\mathrm{Si}$ layer was deposited directly on the chemical $\mathrm{SiO}_{\mathrm{x}}$ buffer layer, a degraded surface passivation was reported for annealing temperatures above $875{ }^{\circ} \mathrm{C}$ [9] or $900{ }^{\circ} \mathrm{C}[6]$ and attributed to a break-up of the $\mathrm{SiO}_{\mathrm{x}}$ buffer layer [13]. 
This break up can be explained with the phase separation $\mathrm{SiO}_{\mathrm{x}} \rightarrow(2-\mathrm{x}) / 2 \mathrm{Si}+(\mathrm{x} / 2)$ $\mathrm{SiO}_{2}$ [12] occurring in thin $\mathrm{SiO}_{x}$ layers sandwiched between two $\mathrm{Si}$ phases, in conjunction with oxygen interstitial generation upon annealing of $\mathrm{SiO}_{2}$ films on $\mathrm{Si}$ wafers in $\mathrm{N}_{2}$ atmosphere $\left(\mathrm{SiO}_{2}+\mathrm{Si} \rightarrow 2 \mathrm{SiO}\right)[24]$.

We explain the beneficial effect of the $\mathrm{nc}^{-\mathrm{SiO}_{\mathrm{x}}}$ layer (Fig. 2a), and the excellent passivation temperature stability shown in Figure $2 \mathrm{~b}, \mathrm{c}$ with an enhanced structural stability of the interfacial $\mathrm{SiO}_{\mathrm{x}}$ buffer layer due to the larger amount of oxygen available from the deposited $\mathrm{nc}_{-} \mathrm{SiO}_{\mathrm{x}}$ layer. With these temperatures as high as $950{ }^{\circ} \mathrm{C}$, an $\mathrm{i} V_{\mathrm{OC}}$ of $723 \mathrm{mV}$ and $J_{0}$ of $11.0 \mathrm{fA} \mathrm{cm}{ }^{-2}$ is reached for the $\mathrm{n}+/ \mathrm{n}$ junction and an $\mathrm{i} V_{\mathrm{OC}}$ of $722 \mathrm{mV}$ and a $J_{0}$ of $8.8 \mathrm{fA} \mathrm{cm}^{-2}$ for $\mathrm{n}+/ \mathrm{n}$ junction, respectively.

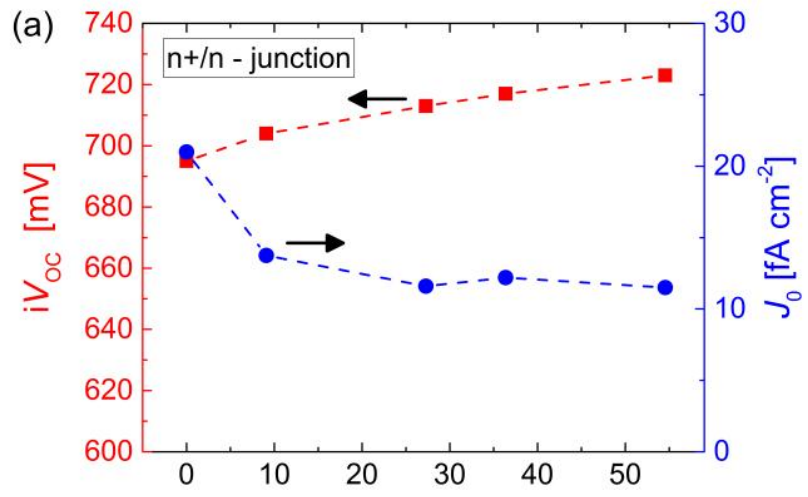

Relative deposition time for $\mathrm{nc}-\mathrm{SiO}_{\mathrm{x}}$ layer [\%]
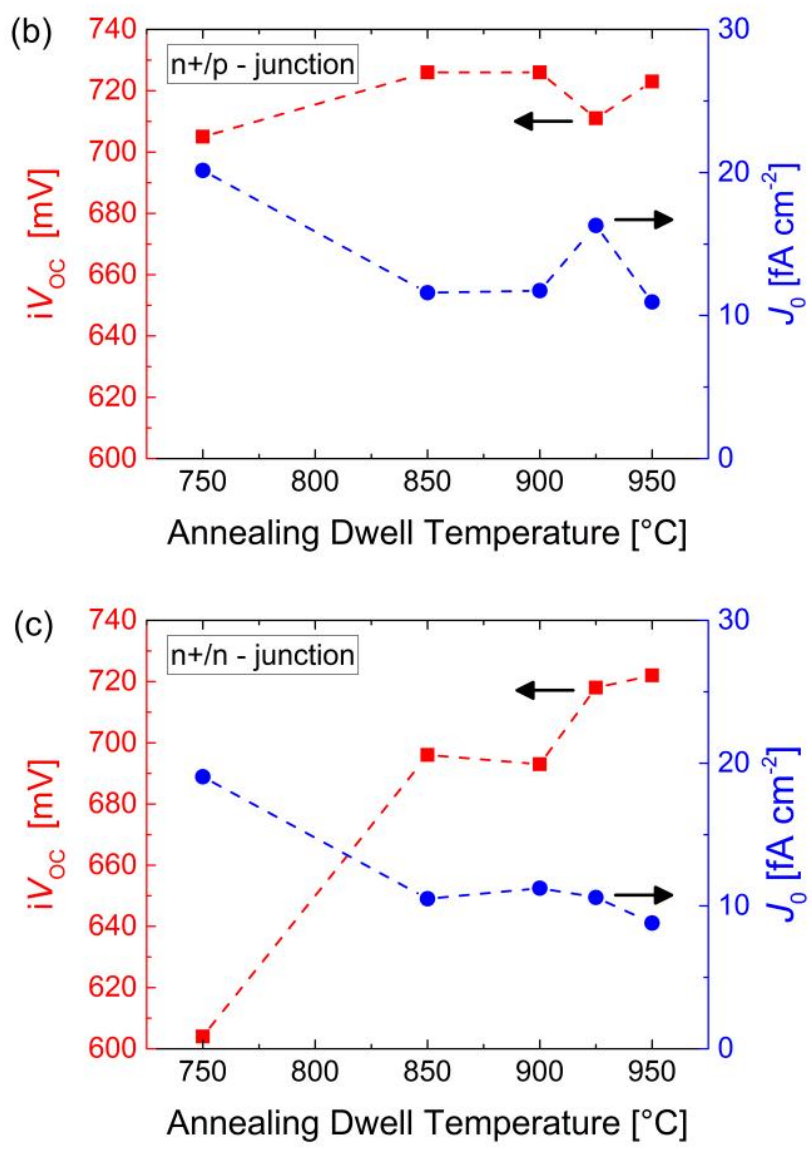

FIG.2. Measured implied open circuit voltage and emitter saturation current density of the contact structure (a) on a n-type wafer annealed at $900^{\circ} \mathrm{C}$ as a function of the relative deposition time of the $\mathrm{nc}-\mathrm{SiO}_{\mathrm{x}}$ layer compared to the deposition time of the whole bilayer stack, (b) on a p-type wafer and (c) on an n-type wafer as a function of the annealing dwell temperature. 


\subsection{Doping profiles}

Figure 3 shows the doping profiles measured by SIMS on the same wafers as discussed above. Within a surface region in the wafer of about $20 \mathrm{~nm}$ from the wafer-SiO $\mathrm{S}_{\mathrm{x}}$ interface, they reveal a similar behavior for all studied temperatures. Beyond that region, they show the expected behavior of deeper in-diffusion at higher temperatures, reaching a depth of $290 \mathrm{~nm}$ for $950{ }^{\circ} \mathrm{C}$. To understand the electrical properties of highly $\mathrm{P}$ doped regions the surface concentration $\mathrm{C}_{\mathrm{s}}$ for the different temperatures can be related to the equilibrium concentration $\mathrm{C}_{\mathrm{eq}}$ and saturation concentration $\mathrm{C}_{\mathrm{sat}}$ given by [25]. For $750{ }^{\circ} \mathrm{C}$, $\mathrm{C}_{\mathrm{s}, 750}=3.00 \cdot 10^{20}$ atoms $\mathrm{cm}^{-3}$ is higher than $\mathrm{C}_{\mathrm{sat}, 750}=2.16 \cdot 10^{20}$ atoms $\mathrm{cm}^{-3}$ meaning that a considerable amount of $\mathrm{P}$ is incorporated partially as $\mathrm{SiP}$ precipitates which are recombination active. For $850{ }^{\circ} \mathrm{C}$ annealing, $\mathrm{C}_{\mathrm{s}, 850}=3.51 \cdot 10^{20}$ atoms $\mathrm{cm}^{-3}$ lies in between $\mathrm{C}_{\mathrm{sat}, 850}=4.05 \cdot 10^{20}$ atoms $\mathrm{cm}^{-3}$ and $\mathrm{C}_{\mathrm{eq}, 850}=2.84 \cdot 10^{20}$ atoms $\mathrm{cm}^{-3}$ denoting that some phosphorus is inactive but not recombination active. After annealing at $900{ }^{\circ} \mathrm{C}$ and higher, $\mathrm{C}_{\mathrm{s}, 950}=3.92 \cdot 10^{20}$ atoms $\mathrm{cm}^{-3}$ is $\lesssim \mathrm{C}_{\mathrm{eq}, 950}=3.89 \cdot 10^{20}$ atoms $\mathrm{cm}^{-3}$, hence indicating that the phosphorus is electrically active. Integrating the doping profiles and calculating the sheet resistance $R_{\mathrm{SH}}$ according to the mobility model of Klaassen et al. as demonstrated by [26] gives values from $300 \Omega / \square$ for $750{ }^{\circ} \mathrm{C}$ down to $160 \Omega / \square$ for $950^{\circ} \mathrm{C}$. To separate the influence of intrinsic (Auger and radiative) recombination from recombination of the surface and explore further optimization potential, we perform simulations of the highly doped region using EDNA [27]. We assume zero Shockley-Read-Hall recombination in the bulk of the emitter. For simplicity we model our structure as a highly doped region in the wafer at a surface with an effective surface recombination velocity SRV. This effective SRV thus lumps all recombination, independent of its exact mechanism, occurring at the interface between wafer and the deposited layer stack and within the layer stack.

The simulation shows that the effective SRV at the wafer/chem. Oxide interface is below $10000 \mathrm{~cm} \mathrm{~s}^{-1}$ for all annealing temperatures $\geq 850{ }^{\circ} \mathrm{C}$. Figure $3 \mathrm{~b}$ shows $J_{0}$ as function of the effective surface recombination velocity for the doping profile of the nc$\mathrm{SiO}_{\mathrm{x}} / \mathrm{nc}$-Si layer stack annealed at $950{ }^{\circ} \mathrm{C}$. The simulation shows that for the doping profile of our $950{ }^{\circ} \mathrm{C}$ sample the saturation current density is largely independent on SRV for an SRV below $1 \cdot 10^{4} \mathrm{~cm} \mathrm{~s}^{-1}$ with a lower limit of $13 \mathrm{fA} \mathrm{cm}^{-2}$. This matches our experimental result within the experimental error, which is estimated to be $\pm 2 \mathrm{fA} \mathrm{cm}^{-2}$. Consequently, our experimental result cannot be improved further by optimizing the recombination properties of the interface or the layer stack.

To explore possibilities for further $J_{0}$ reduction we compare with simulations for complementary error function (ERFC) doping profiles with the same sheet resistance. For the case of an ERFC doping profile with the same phosphorus surface concentration $\mathrm{C}_{\mathrm{S}, 950}$ and same sheet resistance as the $950{ }^{\circ} \mathrm{C}$ annealed sample, leading to a junction depth $\mathrm{z}_{\mathrm{f}}$ of $0.03 \mu \mathrm{m}$, a similar behavior can be seen. Lowering the surface concentration but keeping the sheet resistance constant leads to a deeper junction. For comparison, simulated ERFC doping profiles with deeper junction $\left(\mathrm{C}_{\mathrm{S}}=9.95 \cdot 10^{18}\right.$ atoms $\left.\mathrm{cm}^{-3}, \mathrm{Zf}_{\mathrm{f}}=0.5 \mu \mathrm{m}\right)$ and the junction depth of our $950{ }^{\circ} \mathrm{C}$ sample $\left(\mathrm{C}_{\mathrm{S}}=2.08 \cdot 10^{19}\right.$ atoms $\left.\mathrm{cm}^{-3}, \mathrm{z}_{\mathrm{f}}=0.29 \mu \mathrm{m}\right)$ are added to Figure 3. Consequently, to attain even lower $J_{0}$ values, the surface concentration has to be reduced while increasing the junction depth, an effect that might be accomplished by decreasing the phosphorus concentration in the deposited layer and increasing the annealing dwell time. However, this effect would come at the cost of the $J_{0}$ being more sensitive to the surface recombination properties. Our experimental profile has the advantage that it provides good passivation even in case of comparatively strong surface recombination. 

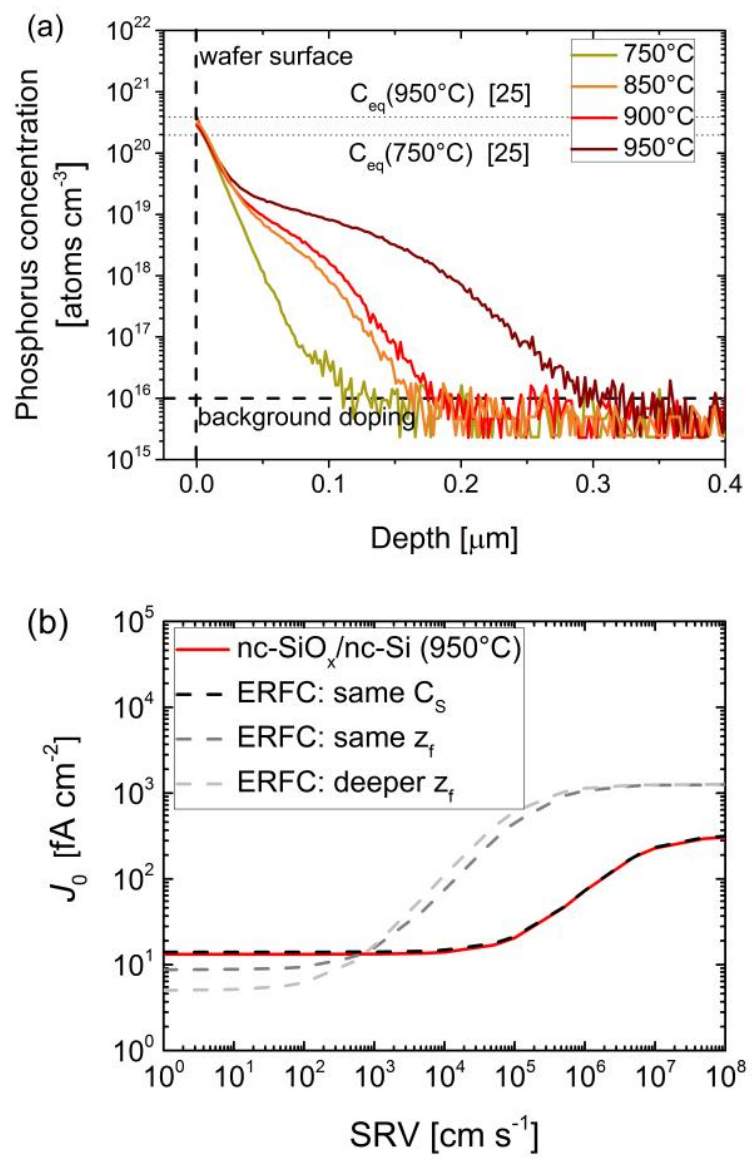

FIG. 3. (a) Doping profile measured by SIMS for different annealing dwell temperatures. (b) Simulation of charge carrier recombination with EDNA [27] out of SIMS doping profiles of (a) for the $950{ }^{\circ} \mathrm{C}$ annealed sample in comparison with generated ERFC doping profiles for same $\mathrm{C}_{\mathrm{s}}$, same $\mathrm{Z}_{\mathrm{f}}$ and a deeper $\mathrm{Z}_{\mathrm{f}}$.

\subsection{Electrical characterization}

TLM measurements were performed using the Berger structure [28]. We extracted the specific contact resistivity $\rho_{\mathrm{c}, \mathrm{TLM}}$ and sheet resistance $R_{\mathrm{SH}, \mathrm{TLM}}$ for structures on p-type wafers as well as on n-type wafers annealed at $900{ }^{\circ} \mathrm{C}$. According to the SIMS measurements shown in Figure 3 these samples feature a highly $\mathrm{P}$ doped region in the wafer about $200 \mathrm{~nm}$ deep underneath the also highly P doped deposited layer stack. Generally, current could flow from one contact to the other both through the deposited layer stack, specifically through the topmost nc-Si layer, and through the in-diffused region in the wafer. In case of an n-type wafer, the lowly doped wafer itself can additionally contribute to conductance. To investigate the current pathway, the region between the TLM pads was repetitively etched for $2 \mathrm{~s}$ in a $\mathrm{SF}_{6} / \mathrm{O}_{2} / \mathrm{Ar}$ plasma using the aluminium pads as etching mask, and the samples were measured after each etch process by TLM. In Figure $4 \mathrm{a}$ and $4 \mathrm{~b}$ a representative behavior of $\rho_{\mathrm{c}, \mathrm{TLM}}$ and $R_{\mathrm{SH}, \mathrm{TLM}}$ as a function of etching depth is shown for $n+/ n$ and $n+/ p$ junctions, respectively. The specific contact resistivity and the sheet resistance both increase upon etching for etch depths exceeding $30 \mathrm{~nm}$ for $\mathrm{n}+/ \mathrm{p}$ junction and $50 \mathrm{~nm}$ for $\mathrm{n}+/ \mathrm{n}$ junction, respectively. Please note that the data points are unequally spaced despite of the constant etch time, which is caused by the lower etch rate of $\mathrm{SiO}_{\mathrm{x}}$ compared to $\mathrm{Si}$. Consequently, the region with closely spaced data points corresponds approximately to the $\mathrm{SiO}_{\mathrm{x}}$ layer (low etch rate).

Both for the $\mathrm{n}+/ \mathrm{n}$ and $\mathrm{n}+/ \mathrm{p}$ junction, $\rho_{\mathrm{c}, \mathrm{TLM}}$ and $R_{\mathrm{SH}, \mathrm{TLM}}$ do not change upon etching of the deposited layer (the first $30 \mathrm{~nm}$ ). This indicates that the deposited layer does not contribute to lateral current transport, but that current rather flows through the wafer 
including the in-diffused region.

The sheet resistance on the $n+/ n$ junction is increasing from $45 \Omega / \square$ before etching to a constant value of $52 \Omega / \square$ after etching over $200 \mathrm{~nm}$ which matches fairly the total calculated sheet resistance of the wafer together with the diffused region at the opposite side of the contacts of $68 \Omega / \square$ (calculated from the wafer thickness $280 \mu \mathrm{m}$, background doping $1.66 \cdot 10^{15}$ atoms $\mathrm{cm}^{-3}$ and ERFC profile $\mathrm{C}_{\mathrm{S}, 900}=2.82 \cdot 10^{20}$ atoms $\mathrm{cm}^{-3}, \mathrm{z}_{\mathrm{f}}=0.027$ $\mu \mathrm{m})$. This small increase indicates the loss of the current pathway within the surface-near region of the wafer below the chemical oxide. For the $n+/ p$ junction the sheet resistance is $70 \Omega / \square$ before etching and is increasing sharply as soon as the diffused region starts to be etched away. For etch depths exceeding $100 \mathrm{~nm}$ the current pathway is too resistive to be measured. Consequently, for the $n+/ p$ structure, the lateral conductive channel is the indiffused $n+$ region only, and current flow is blocked by the $p / n+$ junction.

The specific contact resistivity of the $n+/ n$ junction remains largely unchanged while etching the layer stack, but slightly increases from $86 \mathrm{~m} \Omega \mathrm{cm}^{2}$ to $137 \mathrm{~m} \Omega \mathrm{cm}^{2}$ once the layer stack is etched and also the diffused region within the wafer is removed. For the $n+/ p$ junction, a similar but more pronounced behavior is observed with an increase from $19 \mathrm{~m} \Omega$ $\mathrm{cm}^{2}$ to $85 \mathrm{~m} \Omega \mathrm{cm}^{2}$. Please note that while the structures on $\mathrm{n}+/ \mathrm{p}$ junctions fulfill the assumptions made in the TLM theory, the latter is not strictly valid for the $n+/ n$ junction because the conductive channel is comparatively thick.

Interestingly, in case of the $n+/ p$ junction, the increase of the specific contact resistivity is more pronounced than for the $n+/ n$ junction and occurs at lower etch depth than the increase of the sheet resistance. For the $n+/ n$ junction this is opposite, the sheet resistance starts to increase at an etch depth of $30 \mathrm{~nm}$, but $\rho_{\text {c,TLM }}$ starts to increase only for etch depths of $>60 \mathrm{~nm}$. This hints at current spreading in the first 20 to $40 \mathrm{~nm}$ in the wafer which are doped to $>2 \cdot 10^{19}$ (cf.3 Figure 3a), before the current is laterally transported over the entire depth of the conductive channel. The current flow is qualitatively sketched in Figure 5. Current spreading increases the electrically effective area of the contact. Once the spreading is reduced (here by etching away the conductive channel) the contact resistivity increases. We explain the sharper increase of $\rho_{\mathrm{c}, \mathrm{TLM}}$ in case of the $\mathrm{n}+/ \mathrm{p}$ structures with current spreading being more pronounced than for $n+/ n$ junctions because the current is confined to a thin conductive channel and can spread only on the topmost first $\mathrm{nm}$, see Fig. 5b. In the n-type wafer, on the other hand, current is transported over the entire wafer thickness and the spreading can thus take place over the entire $n+$ region, as depicted in Fig. 5a.

We also performed sintering experiments to investigate the conditions required for establishing a good contact. Samples with the same structure as discussed above (Fig. 4b) were repeatedly sintered for $15 \mathrm{~min}$ on a hot plate in air at temperatures up to $400{ }^{\circ} \mathrm{C}$ and measured after each sintering step. We find a value of $59 \mathrm{~m} \Omega \mathrm{cm}^{2}$ before the first sintering step. However, the specific contact resistivity could not be lowered by sintering for this contact structure.

The TLM measurements presented within this section show that this $\mathrm{nc}_{-} \mathrm{SiO} / \mathrm{nc}-\mathrm{Si}$ layer stack provides not only an excellent surface passivation but also a promising contact resistivity for a sufficient transport of the majority carriers for full-area contacts. 

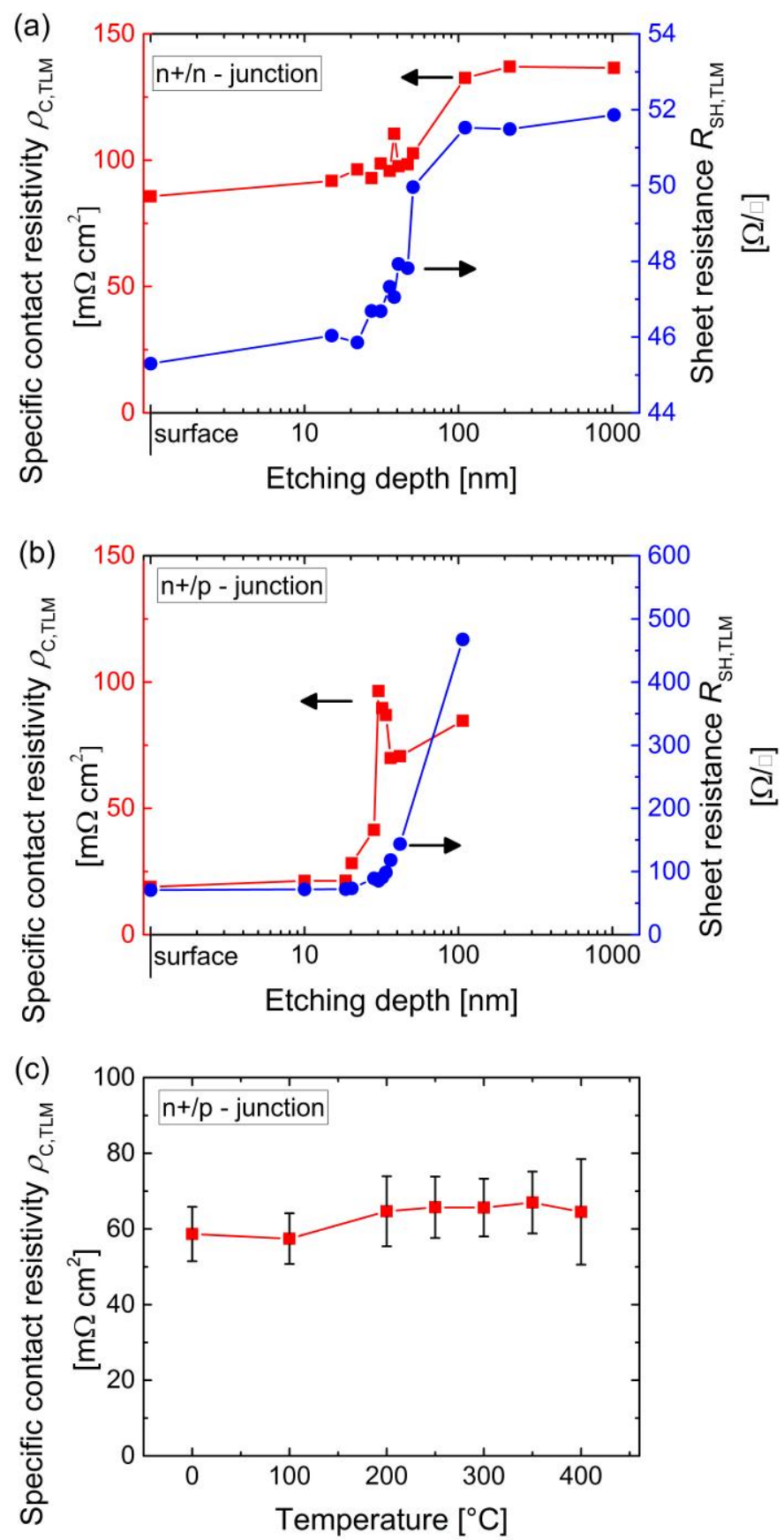

FIG. 4. Specific contact resistivity $\rho_{\mathrm{c}, \mathrm{TLM}}$ and sheet resistance $R_{\mathrm{SH}}$ for the passivating contact depicted in Fig. 1 annealed at $900{ }^{\circ} \mathrm{C}$, as a function of the etching depth for $n+/ n$ junction (a) and $n+/ p$ junction (b). In (c) $\rho_{\mathrm{c}, \text { TLM }}$ is plotted as a function of post-metallization sintering temperature for an $\mathrm{n}+\mathrm{n}$ junction.

(a)

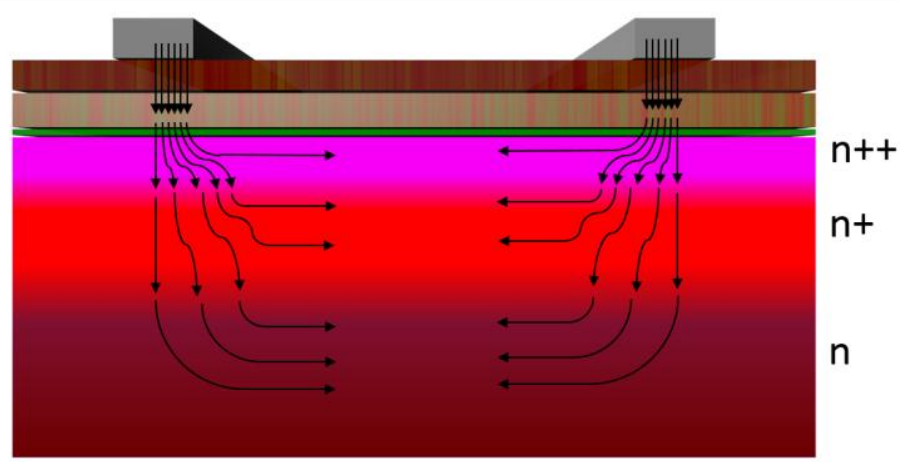


(b)

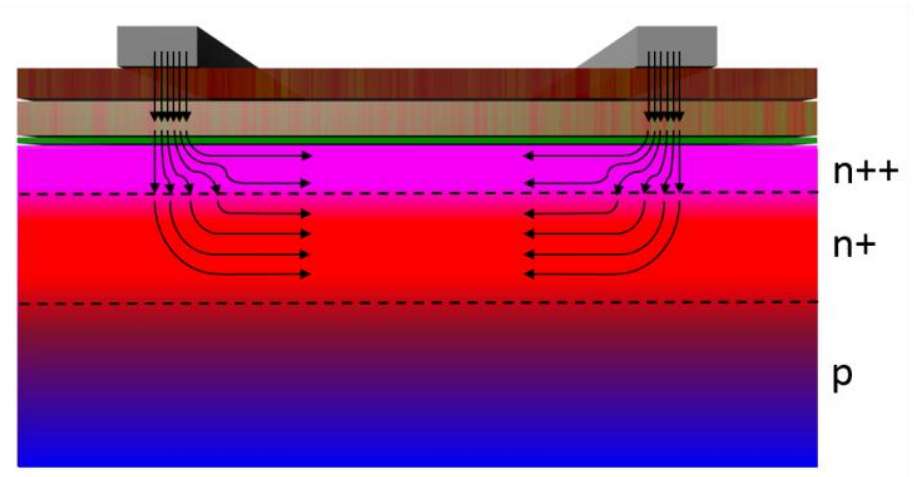

FIG. 5. Qualitative illustration of the current pathway during TLM measurements for an $n+/ n$ junction (a) and an $n+/ p$ junction (b), indicating the current spreading and the electrically effective area.

\subsection{Structural changes}

The crystallinity of the contact layer was analyzed by Raman spectroscopy, as illustrated in Figure 6a. Already in the as-deposited state, the Raman spectrum is dominated by the transverse optical (TO) c-Si phonon with a peak around $520.5 \mathrm{~cm}^{-1}$. However, the signal still shows a pronounced shoulder at wavenumbers between $400 \mathrm{~cm}^{-1}$ and $510 \mathrm{~cm}^{-1}$, which can be attributed to an amorphous Si phase [29]. After $15 \mathrm{~min}$ annealing at $750{ }^{\circ} \mathrm{C}$, measured at position 1, the amorphous fraction is still present. Measuring at a slightly different position only some micrometers apart (position 2), the amorphous fraction is hardly detectable. This means that annealing at $750{ }^{\circ} \mathrm{C}$ for $15 \mathrm{~min}$ is not sufficient to fully crystallize the layers homogeneously. For higher annealing temperatures, the amorphous fraction is decreasing further and lateral inhomogeneities vanish (not shown here). The amorphous contribution almost disappears for a dwell temperature of $950{ }^{\circ} \mathrm{C}$, meaning that the layer is almost fully crystalline.

A deviation of the Raman shift from its equilibrium position is a measure for internal stress in the layer system [30]. To extract the internal stress, the Raman peak is fitted by a Gaussian and the position $\mathrm{x}_{0}$ of the crystalline peak is plotted as a function of the annealing dwell temperature in Figure 6b. The Raman peak shift from the equilibrium position of the c-Si TO phonon band at $520.5 \mathrm{~cm}^{-1}$ is directly proportional to internal stress in the silicon layer $\left(\Delta \mathrm{x}=1 \mathrm{~cm}^{-1} \approx 250 \mathrm{MPa}[30]\right)$. A deviation towards higher wavenumbers is attributed to compressive stress whereas a deviation towards lower wavenumbers means tensile stress. In the as-deposited state the layer system is under tensile stress of $1225 \mathrm{MPa}$. After annealing at $750{ }^{\circ} \mathrm{C}$, the stress at position 1 that had more amorphous phase relaxed to 225 $\mathrm{MPa}$ while the stress at position 2 became compressive $(625 \mathrm{MPa})$. By increasing the temperature to $950{ }^{\circ} \mathrm{C}$ the compressive stress is relaxing to a value of $300 \mathrm{MPa}$. This might be due to a reorganization of the $\mathrm{nc}_{-} \mathrm{SiO}_{\mathrm{x}}$ layer, also accompanied by a phase separation towards a more stoichiometric $\mathrm{SiO}_{2}$. Additionally a restructuration of the mixed phase takes place, which leads to a lower structural defect density as the stress in the film is lowered [31]. 
(a)
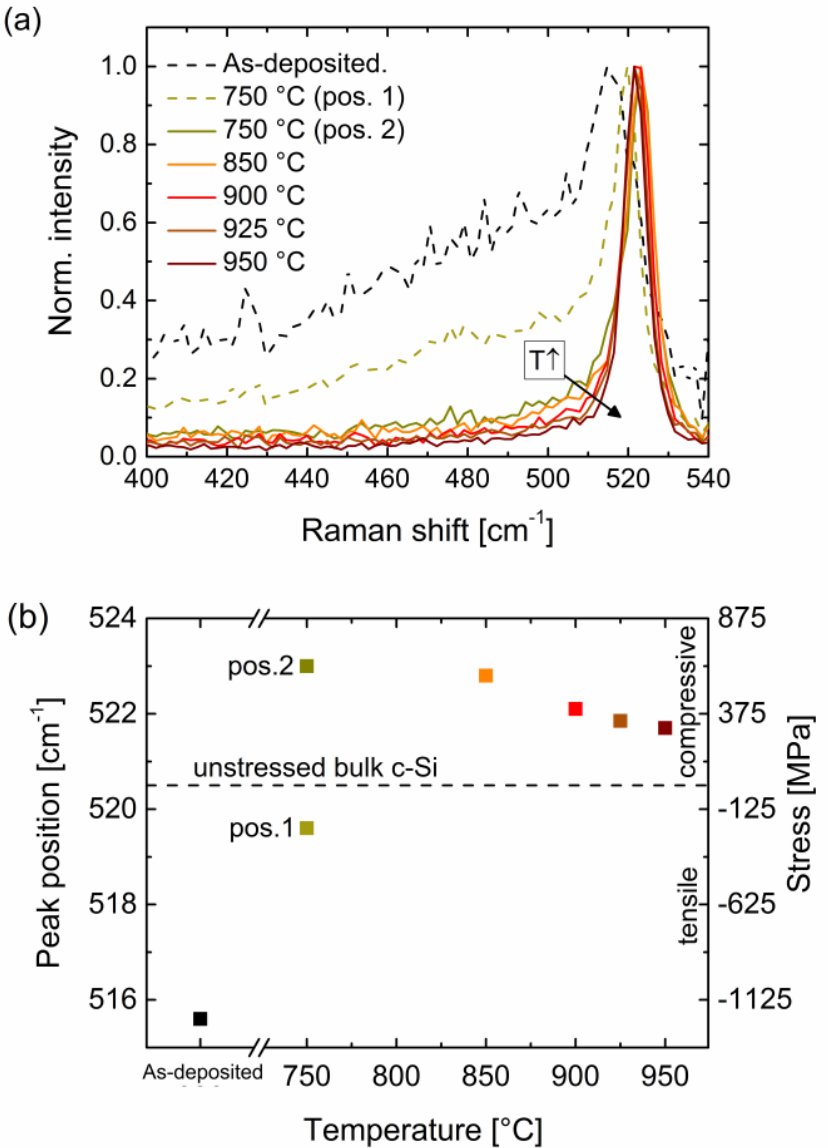

FIG. 6. (a) Raman spectra showing a clear tendency towards lower amorphous fraction with increasing temperature. (b) The stress in the layer system changes from a tensile stress in the as-deposited layer to a strong compressive stress in the layer that relaxes with higher temperature as the position of the c-Si peak is decreasing towards the bulk position at $520.5 \mathrm{~cm}^{-1}$.

The nanostructure of the layer stack and its transformation upon thermal annealing were both investigated by TEM. STEM HAADF images and corresponding EDX maps and line scans of samples as-deposited, annealed at $850{ }^{\circ} \mathrm{C}$ and $900{ }^{\circ} \mathrm{C}$ are shown in Figure 7. Contrast variations in STEM HAADF images are related to differences in thickness (here approximately constant as a result of the FIB-preparation process) and atomic mass, with darker regions highlighting here positions richer in $\mathrm{O}$ and $\mathrm{P}$ when compared to Si-rich regions. In Figure 7, a $\sim 2 \mathrm{~nm}$ thin continuous dark layer is distinguishable at the Si wafer interface in the HAADF image, which according to the EDX map corresponds to $\mathrm{SiO}_{\mathrm{x}}$. As the chemically grown oxide layer is $1.2 \mathrm{~nm}$ thick, the remaining $\sim 0.8 \mathrm{~nm}$ is explained by a contribution from the deposited $\mathrm{SiO}_{\mathrm{x}}$ layer. The EDX O signal is then observed to decrease over a range of $\sim 15 \mathrm{~nm}$ as the layer evolves into phase-separated $\mathrm{SiO}_{\mathrm{x}}$ (dark regions green arrow) and Si (brighter regions - blue arrow) components with increasing Si content towards the top surface. In the upper $10-15 \mathrm{~nm}$, a rather homogeneous silicon layer is visible, corresponding to the deposited Si layer. P doping appears to be homogeneously distributed in the nc-Si phase after deposition of the layers. The top surface is slightly oxidized and exhibits a roughness of $\sim 5 \mathrm{~nm}$.

While the wafer/ $\mathrm{SiO}_{\mathrm{x}}$ interface remains intact when annealing at 850 and $900{ }^{\circ} \mathrm{C}$, the surface oxide layer is observed to thicken with annealing temperature, probably due to residual oxygen present in the furnace (Figure $7 b-c$ ). In addition, the $\mathrm{P}$ distribution within the contact becomes inhomogeneously distributed during annealing. Indeed, as observed in Fig 7b.4, which shows a larger magnification of the structure annealed at $850{ }^{\circ} \mathrm{C}, \mathrm{P}$ has 
accumulated at the interface between the chemical $\mathrm{SiO}_{\mathrm{x}}$ and the wafer (black arrow), while the interfacial $\mathrm{SiO}_{\mathrm{x}}$ itself remains $\mathrm{P}$ depleted.

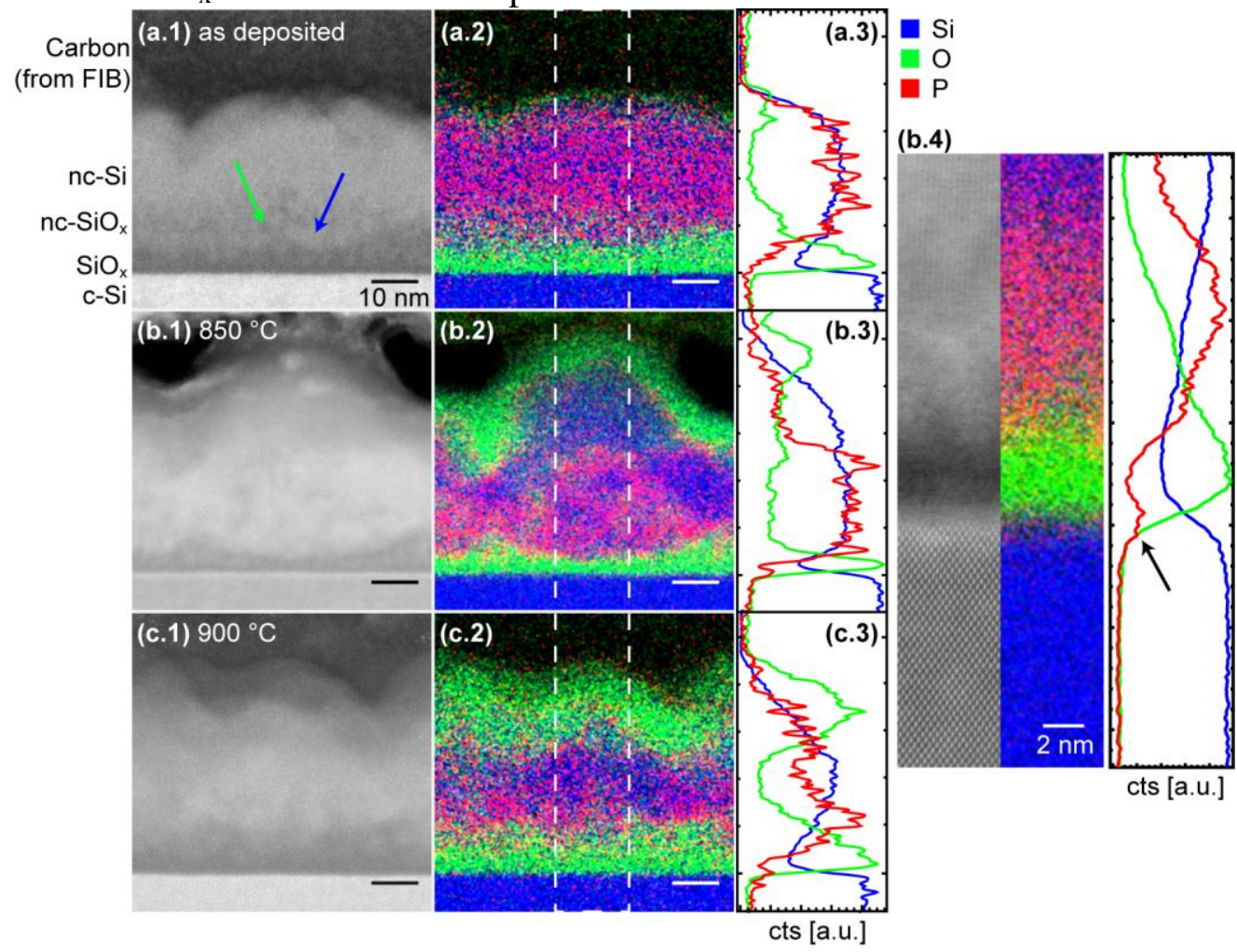

FIG. 7. STEM HAADF images (1) of the bilayer structure as-deposited (a), annealed at $850{ }^{\circ} \mathrm{C}$ (b) and at $900{ }^{\circ} \mathrm{C}$ (c) along with corresponding EDX maps (2) and line scans (3, EDX integrated signal of each element normalized to unity - in arbitrary units, extracted from the dashed region shown in 2). The inset b.4 shows a high-resolution STEM HAADF image, EDX map and line scan of the wafer/contact interface at $850{ }^{\circ} \mathrm{C}$.

In order to investigate in detail the presence of silicon phases within the deposited $\mathrm{SiO}_{\mathrm{x}}$ layer, low-loss EEL spectra were recorded in STEM. Using the methodology presented in [32], [33] , three $4 \mathrm{eV}$ wide images centered at $10 \mathrm{eV}, 17.5 \mathrm{eV}$ and $23 \mathrm{eV}$ were extracted from the spectrum image. From the first and last images, a linear background was extrapolated and subtracted to the second image taken at the position of the Si plasmon peak as illustrated in Figure 8a. The contrast in the resulting image is related to differences in plasmon signal between $\mathrm{Si}$ (bright) and $\mathrm{SiO}_{\mathrm{x}}$ (dark) and hence reveals fluctuations in composition within the $\mathrm{SiO}_{\mathrm{x}}$ layer. At the wafer surface, a 2-3 nm continuous $\mathrm{SiO}_{\mathrm{x}}$ layer is distinguishable both after deposition and annealing at $850{ }^{\circ} \mathrm{C}$ (Fig. 8b-c). Directly above, the results demonstrate the mixed-phase nature of the deposited $\mathrm{SiO}_{\mathrm{x}}$ layer even after annealing, with vertically oriented silicon rich phases (arrowed in Fig. 8b-c) of a few nanometers in diameter extending throughout the oxide matrix up to the silicon layer deposited on top. Please note that the resolution of the STEM EEL spectrum images is limited by the delocalization of the plasmon signal (on the order of $2 \mathrm{~nm}$ [34]) which is inherent to the technique. 


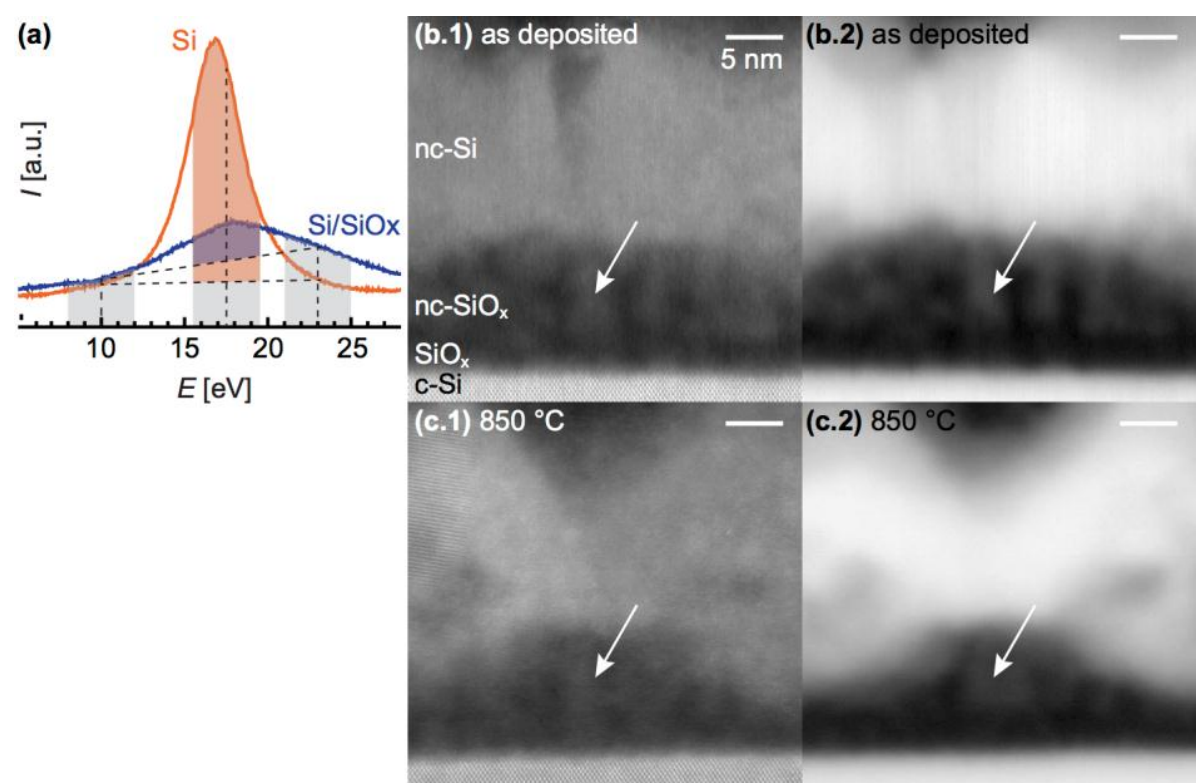

FIG. 8. (a) EEL spectra of c-Si and mixed $\mathrm{Si} / \mathrm{SiO}_{\mathrm{x}}$ regions; (b.1-2) STEM HAADF and corresponding EELS spectrum image of plasmons after background subtraction (colored region of the spectrum shown in a) of the as-deposited sample; (c1-2) STEM HAADF and plasmons EELS spectrum image of the sample annealed at $850{ }^{\circ} \mathrm{C}$.

The crystallinity of the layers was assessed by high-resolution TEM imaging. Figure 9 shows HRTEM micrographs of the contact as-deposited and annealed at 850 and $900{ }^{\circ} \mathrm{C}$ along with their Fourier transforms and colored inverse Fourier transforms of selected reflections. The results demonstrate a clear increase in crystallinity of the contact layer when annealed at $850{ }^{\circ} \mathrm{C}$ with grain sizes of up to $\sim 10 \mathrm{~nm}$, while annealing at $900{ }^{\circ} \mathrm{C}$ leads to larger grains up to $\sim 30 \mathrm{~nm}$. This finding corroborates the high crystallinity observed by Raman spectroscopy shown in Figure 6a. Moreover, the crystalline Si phases matrix extend locally to about $3 \mathrm{~nm}$ of the wafer interface building a percolating crystalline network through most of the contact structure. From comparison with Figure 8 we conclude that the $\mathrm{Si}$ filaments in the lower part of the deposited $\mathrm{SiO}_{\mathrm{x}}$ layer remain amorphous even after annealing, while silicon crystallites are observed mostly further away from the interface and in the nc-Si layer. At the interface with the wafer, the $\mathrm{SiO}_{\mathrm{x}}$ appears to remain amorphous. 


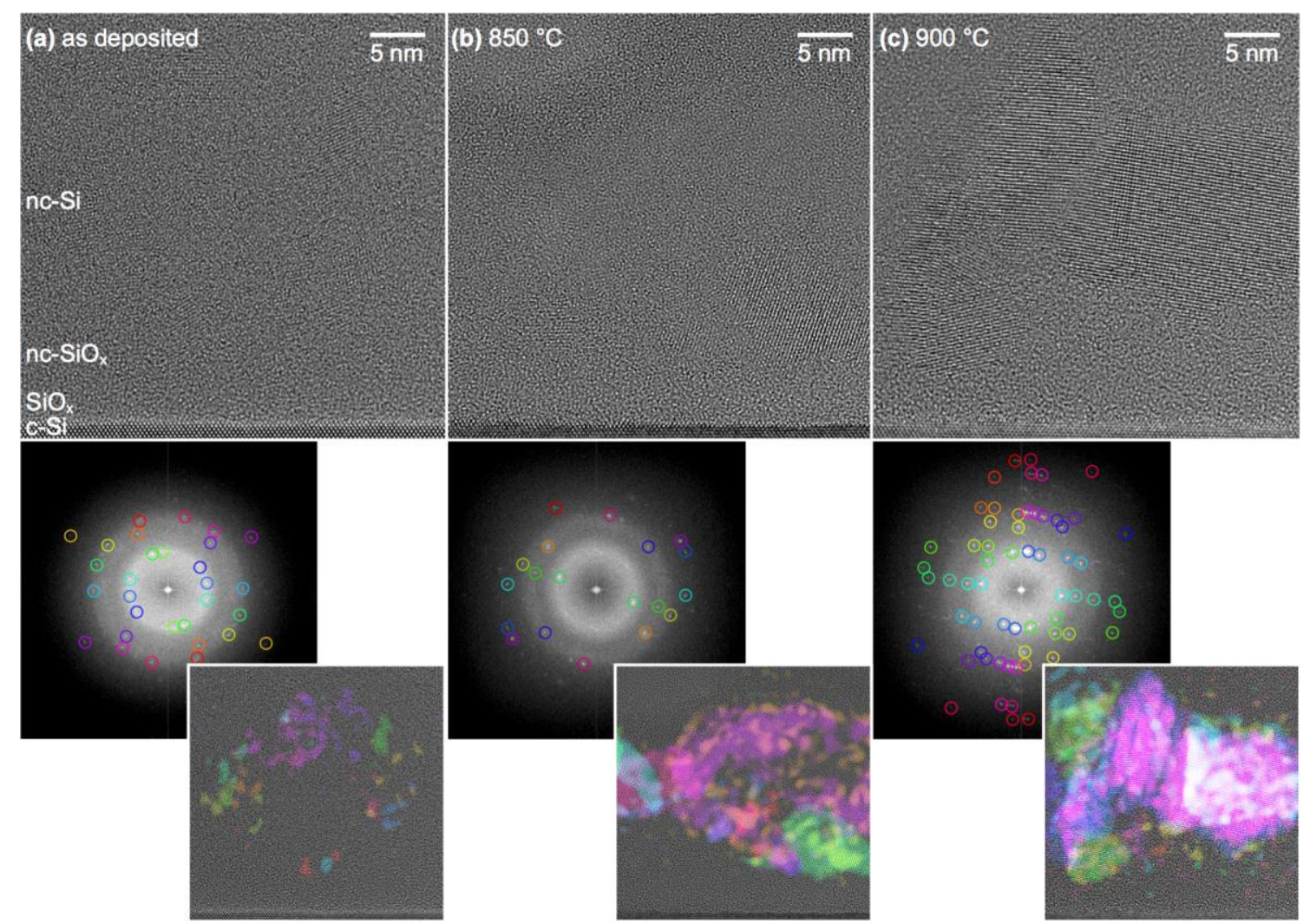

FIG. 9. HRTEM micrographs, Fourier transforms and inverse Fourier transforms of selected reflections colored and superimposed to the HRTEM image of the contact structure as-deposited (a), annealed at $850{ }^{\circ} \mathrm{C}$ (b) and annealed at $900{ }^{\circ} \mathrm{C}$ (c)

\section{CONCLUSION}

A novel passivating electron contact structure based on a tunnel-oxide and a highly phosphorus-doped nc-SiO $/ \mathrm{nc}-\mathrm{Si}$ double layer is presented. High-resolution (S)TEM micrographs and EDX chemical maps show an interfacial amorphous $\mathrm{SiO}_{\mathrm{x}}$ layer of ca. $2 \mathrm{~nm}$ thickness, followed by a nanocrystalline $\mathrm{SiO}_{\mathrm{x}} / \mathrm{Si}$ mixed-phase layer and a continuous nanocrystalline $\mathrm{Si}$ layer. The mixed-phase layer (called $\mathrm{nc}-\mathrm{SiO}_{\mathrm{x}}$ ) consists of a $\mathrm{SiO}_{\mathrm{x}}$ matrix with $\mathrm{Si}$ filaments extending through almost the entire $\mathrm{SiO}_{\mathrm{x}}$ layer, and shows increasing $\mathrm{Si}$ concentration and crystallinity towards its top interface. The addition of the $n c-\mathrm{SiO}_{\mathrm{x}}$ layer between the chemical oxide and the nc-Si layer was shown to enhance the thermal stability of the surface passivation. The amorphous volume fraction decreases significantly upon thermal annealing at temperatures $\geq 800{ }^{\circ} \mathrm{C}$, which is believed to be beneficial for electrical transport and a promising result towards minimized parasitic absorption. In-diffusion of phosphorus creates a doping profile with surface concentration of $3.92 \cdot 10^{20}$ atoms $\mathrm{cm}^{-3}$. Thus, an excellent surface passivation is achieved with emitter saturation currents of $11.0 \mathrm{fA} \mathrm{cm}$ - for $\mathrm{n}+/ \mathrm{p}$ junction and $8.8 \mathrm{fA} \mathrm{cm}^{-2}$ for $\mathrm{n}+/ \mathrm{n}$ junctions, respectively, yielding specific contact resistivities between $19 \mathrm{~m} \Omega \mathrm{cm}^{2}$ and $86 \mathrm{~m} \Omega \mathrm{cm}^{2}$.

\section{ACKNOWLEDGEMENT}

The authors gratefully acknowledge support by the Swiss National Science Foundation (SNF) under grant No. 200021_14588/1 and No. IZLIZ2_156641 and by the Swiss Federal Office for Energy (SFOE) under grant No. SI/501253-01. The Interdisciplinary Centre for Electron Microscopy of EPFL is acknowledged for FIB and TEM access. The authors thank also Aïcha Hessler-Wyser for her support and discussions. 


\section{REFERENCES}

[1] IEA-PVPS, "TRENDS 2014 in Photovoltaic Applications: Survey Report of Selected IEA Countries between 1992 and 2013," 2014.

[2] A. Cuevas, "Physical model of back line-contact front-junction solar cells," J. Appl. Phys., vol. 113, no. 16, 2013.

[3] Y. H. Kwark, R. Sinton, and R. M. Swanson, "SIPOS Heterojunction contacts to silicon (1984)," vol. 94305, no. 415, pp. 742-745, 1984.

[4] E. Yablonovitch, T. Gmitter, R. M. Swanson, and Y. H. Kwark, "A $720 \mathrm{mV}$ open circuit voltage SiOx:c-Si:SiOx double heterostructure solar cell,” Appl. Phys. Lett., vol. 47, no. 11, p. 1211, 1985.

[5] J. Y. Gan and R. M. Swanson, "Polysilicon Emitters for Silicon Concentrator Solar Cells," Proc. 21st IEEE PVSC, pp. 245-250, 1990.

[6] F. Feldmann, M. Bivour, C. Reichel, H. Steinkemper, M. Hermle, and S. W. Glunz, "Tunnel oxide passivated contacts as an alternative to partial rear contacts," Sol. Energy Mater. Sol. Cells, vol. 131, pp. 46-50, 2014.

[7] U. Römer, R. Peibst, T. Ohrdes, B. Lim, J. Krügener, E. Bugiel, T. Wietler, and R. Brendel, "Recombination behavior and contact resistance of $\mathrm{n}+$ and $\mathrm{p}+$ poly-crystalline $\mathrm{Si} /$ mono-crystalline $\mathrm{Si}$ junctions,” Sol. Energy Mater. Sol. Cells, vol. 131, pp. 85-91, 2014.

[8] D. L. Young, W. Nemeth, S. Grover, A. Norman, B. G. Lee, and P. Stradins, "Carrier-selective, passivated contacts for high efficiency silicon solar cells based on transparent conducting oxides," 2014 IEEE 40th Photovolt. Spec. Conf., pp. 1-5, 2014.

[9] Y. Tao, E. L. Chang, A. Upadhyaya, B. Roundaville, Y. Ok, K. Madani, C. Chen, K. Tate, V. Upadhyaya, F. Zimbardi, J. Keane, A. Payne, and A. Rohatgi, "730 mV implied Voc enabled by tunnel oxide passivated contact with PECVD grown and crystallized n+ polycrystalline Si," 2015 IEEE 42nd Photovolt. Spec. Conf., pp. 1-5, 2015.

[10] S. W. Glunz, F. Feldmann, A. Richter, M. Bivour, C. Reichel, H. Steinkemper, J. Benick, and M. Hermle, "THE IRRESISTIBLE CHARM OF A SIMPLE CURRENT FLOW PATTERN - 25\% with a solar cell featuring a full area back contact," Proc. 31th EUPVSEC, 2015.

[11] S. J. Pearton, J. W. Corbett, and M. Stavola, Hydrogen in Crystalline Semiconductors. Springer, 1992.

[12] M. Zacharias and P. Streitenberger, "Crystallization of amorphous superlattices in the limit of ultrathin films with oxide interfaces," Phys. Rev. B, vol. 62, no. 12, pp. 8391-8396, Sep. 2000.

[13] G. R. Wolstenholme, N. Jorgensen, P. Ashburn, and G. R. Booker, "An investigation of the thermal stability of the interfacial oxide in polycrystalline silicon emitter bipolar transistors by comparing device results with high-resolution electron microscopy observations," J. Appl. Phys., vol. 61, no. 1, pp. 225-233, 1987.

[14] A. Moldovan, F. Feldmann, G. Krugel, M. Zimmer, J. Rentsch, M. Hermle, A. Roth-Fölsch, K. Kaufmann, and C. Hagendorf, "Simple cleaning and conditioning of silicon surfaces with UV/ozone Sources,” Energy Procedia, vol. 55, pp. 834-844, 2014.

[15] F. Feldmann, M. Bivour, and C. Reichel, "Advanced Passivated Contacts and their Applications to High-efficiency Cells,” NREL Silicon Work., 2015.

[16] P. Cuony, M. Marending, D. T. L. Alexander, M. Boccard, G. Bugnon, M. Despeisse, and C. Ballif, "Mixed-phase p-type silicon oxide containing silicon nanocrystals and its role in thin-film silicon solar cells," Appl. Phys. Lett., vol. 97, no. 21, p. 213502, 2010.

[17] P. Brüesch, T. Stockmeier, F. Stucki, and P. A. Buffat, "Physical properties of semi-insulating polycrystalline silicon. I. Structure, electronic properties, and electrical conductivity," J. Appl. Phys., vol. 73, no. 11, pp. 7677-7689, 1993. 
[18] Y. Pan, "Study on the optical absorption of oxygen-doped polysilicon thin films," Opt. Eng., vol. 32, no. 3, p. 589, 1993.

[19] H. Kobayashi Asuha, O. Maida, M. Takahashi, and H. Iwasa, "Nitric acid oxidation of Si to form ultrathin silicon dioxide layers with a low leakage current density," J. Appl. Phys., vol. 94, no. 11, p. 7328, 2003.

[20] N. E. Grant and K. R. McIntosh, "Surface Passivation Attained by Silicon Dioxide Grown at Low Temperature in Nitric Acid,” 24th Eur. Photovolt. Sol. Energy Conf., pp. 1676-1679, 2009.

[21] D. E. Kane and R. M. Swanson, "Measurement of the emitter saturation current by a contactless photoconductivity decay method," Proc. 18th IEEE Photovolt. Spec. Conf., pp. 578-583, 1985.

[22] M. Ledinsky, A. Vetushka, J. Stuchlik, T. Mates, A. Fejfar, J. Kocka, and J. Stepanek, “Crystallinity of the mixed phase silicon thin films by Raman spectroscopy," J. Non. Cryst. Solids, vol. 354, no. 19-25, pp. 2253-2257, 2008.

[23] W. S. Yoo, H. Harima, and M. Yoshimoto, "Polarized Raman Signals from Si Wafers : Dependence of In-Plane Incident Orientation of Probing Light,” vol. 4, no. 9, pp. 356-363, 2015.

[24] R. A. B. Devine, D. Mathiot, W. L. Warren, and B. Aspar, "O interstitial generation and diffusion in high temperature annealed Si / SiO2 / Si structures,” J. Appl. Phys., vol. 79, pp. 2302-2308, 1996.

[25] S. Solmi, a. Parisini, R. Angelucci, a. Armigliato, D. Nobili, and L. Moro, "Dopant and carrier concentration in Si in equilibrium with monoclinic SiP precipitates," Phys. Rev. B, vol. 53, no. 12, pp. 7836-7841, 1996.

[26] D. B. M. Klaassen, "A unified mobility model for device simulation-I. Model equations and concentration dependence," Solid State Electron., vol. 35, no. 7, pp. 953-959, 1992.

[27] PVLighthouse, "EDNA2," 2016. [Online]. Available: https://www2.pvlighthouse.com.au/calculators.

[28] H. H. Berger, "Contact resistance and contact resistivity," J. Electrochem. Soc., vol. 119, no. 4, p. 507, 1972.

[29] Z. Iqbal and S. Veprek, "Raman scattering from hydrogenated microcrystalline and amorphous silicon,” J. Phys. C Solid State Phys., vol. 377, 1982.

[30] I. DeWolf, "Micro-Raman spectroscopy to study local mechanical stress in silicon integrated circuits," Semicond. Sci. Technol., vol. 11, no. 2, pp. 139-154, 1996.

[31] M. Zacharias, J. Bläsing, P. Veit, L. Tsybeskov, K. Hirschman, and P. M. Fauchet, "Thermal crystallization of amorphous $\mathrm{Si} / \mathrm{SiO}[$ sub 2] superlattices," Appl. Phys. Lett., vol. 74, no. 1999, p. 2614, 1999.

[32] S. Schamm, C. Bonafos, H. Coffin, N. Cherkashin, M. Carrada, G. Ben Assayag, A. Claverie, M. Tencé, and C. Colliex, "Imaging Si nanoparticles embedded in SiO2 layers by (S)TEM-EELS," Ultramicroscopy, vol. 108, no. 4, pp. 346-357, 2008.

[33] P. Cuony, D. T. L. Alexander, I. Perez-Wurfl, M. Despeisse, G. Bugnon, M. Boccard, T. Söderström, A. Hessler-Wyser, C. Hébert, and C. Ballif, "Silicon filaments in silicon oxide for next-generation photovoltaics," Adv. Mater., vol. 24, no. 9, pp. 1182-1186, 2012.

[34] R. F. Egerton, "Electron energy-loss spectroscopy in the TEM," Reports Prog. Phys., vol. 72, no. 1, p. $016502,2008$. 